\title{
Enhancement of entrapping ability of dendrimers by a cubic silsesquioxane core.
}

\section{$\operatorname{AUTHOR}(\mathrm{S})$ :}

Tanaka, Kazuo; Inafuku, Kenichi; Naka, Kensuke; Chujo, Yoshiki

\section{CITATION:}

Tanaka, Kazuo ...[et al]. Enhancement of entrapping ability of dendrimers by a cubic silsesquioxane core.. Organic \& biomolecular chemistry 2008, 6(21): 3899-3901

\section{ISSUE DATE:}

2008-11-07

URL:

http://hdl.handle.net/2433/123365

\section{RIGHT:}

Org. Biomol. Chem., 2008, 6(21), pp.3899-3901 - Reproduced by permission of The Royal Society of Chemistry (RSC); This is not the published version. Please cite only the published version.; この論文は出版社版でありません。引用の際には出版社版をご確認 ご利用ください。 


\title{
Enhancement of Entrapping Ability by Cubic Silsesquioxane Core in Dendrimers
}

\author{
Kazuo Tanaka, ${ }^{a}$ Kenichi Inafuku, ${ }^{a}$ Kensuke Naka ${ }^{b}$ and Yoshiki Chujo ${ }^{* a}$ \\ Receipt/Acceptance Data [DO NOT ALTER/DELETE THIS TEXT] \\ ${ }_{5}$ Publication data [DO NOT ALTER/DELETE THIS TEXT] \\ DOI: 10.1039/b000000x [DO NOT ALTER/DELETE THIS TEXT]
}

We report that the POSS core can enhance the entrapping ability of the dendrimer. Compared to the G2 PAMAM dendrimer, the G2 POSS-core dendrimer can entrap a larger amount of guest 10 molecules without loss of affinity, and consequently the watersolubility of the entrapped guest molecules can be increased. In addition, we demonstrate that the entrapped fluorophore into the G2 POSS-core dendrimer was prevented from the fluorescence photobleaching.

15 Water-soluble dendrimers have been used as the convenient vehicles for drug delivery not only due to the enhancement of water-solubility to the hydrophobic molecules by the packing into the internal space but also due to the site-selective distribution by the size tuning and the peripheral modification. Poly(amidoamine)

20 (PAMAM) dendrimers, which are well known as the typical watersoluble dendrimers, have been proposed as mimics of charged micelles or proteins because of their unimolecular characters, and their physicochemical properties and biological behaviors have been investigated extensively. ${ }^{[1]}$

25 The inside of dendrimers can generate the distinctive space in the solution. The different polarity, solvation, and structure can provide dendrimers with the characteristics as the reaction fields, the molecular gates, and the templates for the synthesis of nanoparticles. ${ }^{[2-4]}$ The core of the dendrimers plays a crucial role in

30 these properties via the predominance on the total shape and the groove between dendrons, particularly in the early generation. From this view point, the polyhedral structure of the polyhedral oligomeric silsesquioxane (POSS) core is very attractive because the internal space of POSS-core dendrimers has a possibility to 35 contribute to generate new properties because of their threedimensional architecture (Fig. 1). ${ }^{[5]}$

Herein, we report that the POSS core can enhance the entrapping ability to the dendrimers in aqueous media. Compared to the G2 PAMAM dendrimer, the G2 POSS-core dendrimer can capture a 40 larger amount of guest molecules without loss of the affinity, and consequently the water-solubility of the guest molecules can be increased. In addition, we demonstrate the photochemical

\footnotetext{
${ }^{a}$ Department of Polymer Chemistry

Graduate School of Engineering, Kyoto University

Katsura, Nishikyo-ku, Kyoto 615-8510 Japan

Fax: (+81) 75-383-2605

E-mail: chujo@chujo.synchem.kyoto-u.ac.jp

${ }^{b}$ Department of Chemistry and Materials Technology

Graduate School of Science and Technology

Kyoto Institute of Technology

Sakyo-ku, Kyoto 606-8585 Japan

$\dagger$ Electronic Supplementary Information (ESI) available: [details of any supplementary information available should be included here]. See
} http://dx.doi.org/10.1039/b000000x/

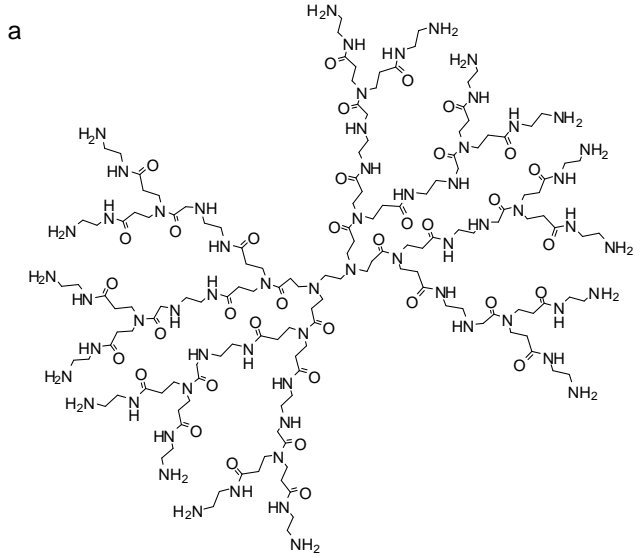

b

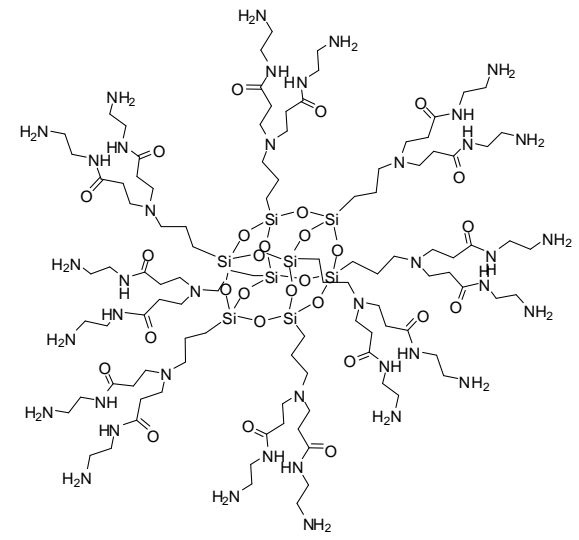

Fig. 1 Chemical structures of (a) the G2 PAMAM dendrimer and (b) the G2 POSS-core dendrimer.

application to prevent the entrapped fluorophore from the fluorescence photobleaching.

45 Previous reports suggested that POSS-core dendrimers have a relatively globular conformation and few entanglements of their branches with a high proportion of terminal functional groups positioned on the external surface of the dendrimers even in earlier generations. $^{[6]}$ In contrast, the early generation PAMAM ${ }_{50}$ dendrimers can form an open structure. ${ }^{[7]}$ Therefore, we expected that the difference of the core between the G2 PAMAM and POSScore dendrimer should influence on the quantity, the universality, and the affinity with the G2 POSS-core dendrimer in the entrapment of the guest molecules.

55 In order to evaluate the entrapping ability of each dendrimer, the enhancement solubilization factor (ESF) defined as the number of moles of compound solubilized per number of moles of the 
Table 1 The enhancement solubilization factor (ESF) and the dissociation temperature $\left(T_{\mathrm{d}}\right)$ for the polycyclic aromatic compounds

\begin{tabular}{|c|c|c|c|c|c|c|c|c|}
\hline \multirow[b]{2}{*}{ Dendrimers } & \multicolumn{2}{|c|}{ Anthracene } & \multicolumn{2}{|c|}{ Naphthacene } & \multicolumn{2}{|c|}{ Phenanthrene } & \multicolumn{2}{|c|}{ Pyrene } \\
\hline & ESF & $T_{\mathrm{d}}\left({ }^{\circ} \mathrm{C}\right)^{a}$ & ESF & $T_{\mathrm{d}}\left({ }^{\circ} \mathrm{C}\right)^{a}$ & ESF & $T_{\mathrm{d}}\left({ }^{\circ} \mathrm{C}\right)^{a}$ & ESF & $T_{\mathrm{d}}\left({ }^{\circ} \mathrm{C}\right)^{a}$ \\
\hline G2 POSS-core & 0.6 & 47.3 & 1.2 & $>80^{b}$ & 1.4 & 62.5 & 0.8 & 46.5 \\
\hline G2 PAMAM & 0.6 & 49.0 & 1.2 & $>80^{b}$ & 0.1 & 53.1 & 0.5 & 47.0 \\
\hline
\end{tabular}

${ }^{a}$ All $T_{\mathrm{d}} \mathrm{S}$ of the complexes $(10 \mu \mathrm{M})$ were taken in $50 \mathrm{mM}$ sodium phosphate buffers $(\mathrm{pH}=7.0)$. First derivatives were calculated to determine $T_{\mathrm{d}}$ values.

${ }^{b} T_{\mathrm{d}} \mathrm{S}$ were not determined because of too high affinity.

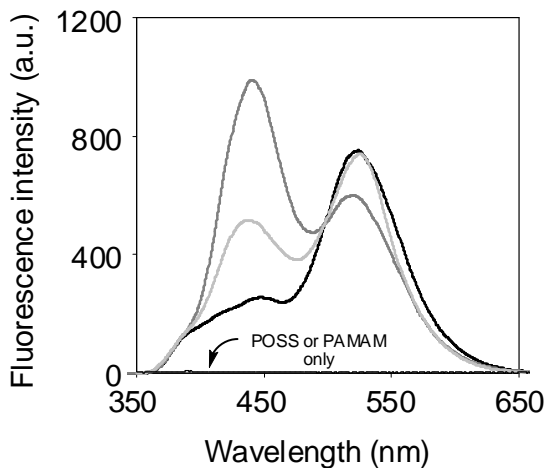

Fig. 2 Fluorescence spectra of $1 \mu \mathrm{M}$ DAN in the absence (black line) and presence of $10 \mu \mathrm{M}$ the dendrimers (G2 POSS-core dendrimer: dark gray line, G2 PAMAM dendrimer: light gray line) in $50 \mathrm{mM}$ sodium phosphate buffer $(\mathrm{pH}=7.0)$ at $25^{\circ} \mathrm{C}$. Excitation wavelength was $300 \mathrm{~nm}$.

dendrimers was evaluated with the G2 PAMAM and POSS-core dendrimer in $50 \mathrm{mM}$ sodium phosphate buffer $(\mathrm{pH}=7.0)$ at ${ }_{60} 25{ }^{\circ} \mathrm{C} .{ }^{[8]}$ Samples containing the guest molecules and each dendrimer were sonicated for $30 \mathrm{sec}$ and allowed to equilibrate in darkness overnight for the complexation with the guest molecules. The ESF values were calculated from the difference between the solubility of the guest molecules in the presence and absence of ${ }_{65}$ dendrimers with UV absorption spectra. ${ }^{[9]}$ The results are summarized in Table 1. The G2 POSS-core dendrimer can capture the larger amounts of the planner molecules, phenanthrene and pyrene, than those of the G2 PAMAM dendrimer, while similar amounts of the linear molecules, antharacene and naphthacene were 70 entrapped into both dendrimers. The globular structure of the POSS-core dendrimer could generate the hydrophobic cavity for entrapping the planner molecules.

Affinity of entrapped molecules with dendrimers was estimated by the dissociation temperature $\left(T_{\mathrm{d}}\right)$ obtained from variable 75 temperature UV measurements (Table 1). ${ }^{[10]}$ Each guest molecule showed different UV absorbance between inside and outside dendrimers. We decided the $T_{\mathrm{d}}$ values between the guest molecules and the dendrimers from the chromism in the UV spectra. Except the complex with naphthacene, the traces of the absorbance 80 alteration of aromatic rings in the sample solutions exhibited the sigmoid curves, and the $T_{\mathrm{d}}$ values were determined from the temperatures at the flexion points on the curves. The affinities with anthracene, naphthacene, and pyrene were not significantly influenced by the POSS-core substitution. Large stabilization was 85 observed even in the complex with phenanthrene which was hardly captured by the G2 PAMAM dendrimer. Including of the result of the ESF measurements, these data suggest that the water-exclusive space and less entanglement of dendrons around the POSS core could produce the favorable pockets for molecular capturing.

90 For investigating the heterogeneous environments of the dendrimers by the photochemical approach, we used 6dimethylamino-2-naphthaldehyde (DAN) known as a micro- a)<smiles>CCN=c1cc2oc3cc(NCC)c(C)cc3c(-c3ccccc3OCC)c-2cc1C</smiles>

rhodamin 6G (Rh6G)

b)

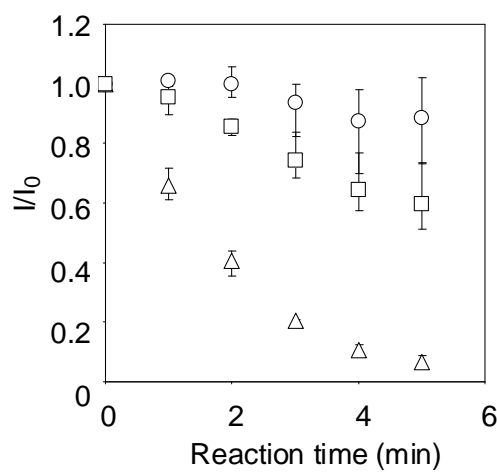

Fig. 3 (a) Chemical structure of Rh6G. (b) Time-course of the decrease of the fluorescence intensity of Rh6G (1 $\mu \mathrm{M})$ (triangular dots) in aerated water in the presence of $10 \mu \mathrm{M} \mathrm{G} 2$ POSS-core dendrimer (circular dots) or G2 PAMAM dendrimer (square dots) followed through the decrease of the fluorescence emission with increasing time of UV irradiation with a low pressure mercury lamp at $25{ }^{\circ} \mathrm{C}$. The data points represent the average of three sets of independent experiments, and error bars represent standard deviation.

environment-sensitive fluorescent probe ${ }^{[11]}$ All DAN molecules in the solution were entrapped into the excess of the dendrimers. The ${ }_{95}$ sample containing $1 \mu \mathrm{M}$ DAN in $50 \mathrm{mM}$ sodium phosphate buffer $(\mathrm{pH}=7.0)$ excited at $300 \mathrm{~nm}$ wavelength gave fluorescence emission at $525 \mathrm{~nm}$ (Fig. 2). By the complexation with both of the dendrimers $(10 \mu \mathrm{M})$, the new peak of fluorescence emission appeared at $440 \mathrm{~nm}$. In particular, the fluorescence spectra of the 100 complex with the G2 POSS-core dendrimer showed the significant change from that of the sample without dendrimer. These data suggest that the G2 POSS-core dendrimer could make stronger interaction with the guest molecules than the G2 PAMAM dendrimer, and it is implied that this interaction could contribute to 105 the enhancement of the amount of the guest molecules encaptured by the G2 POSS-core dendrimer.

For the repetitive and longitudinal measurements with microscopy or time-resolve spectroscopy, efforts have been made to improve the fluorescence of the dyes, in regard to their stability 110 towards adsorption, aggregation, and photochemical decomposition, by use of additives. ${ }^{[12-15]}$ We demonstrate the prevention of fluorescence photobleaching of rhodamine $6 \mathrm{G}(\mathrm{Rh} 6 \mathrm{G})$, which is the most important fluorescent dye as shown by the classical and 
contemporary applications, by the entrapment with POSS-core 115 dendrimers (Fig. 3a). ${ }^{[12,16]}$ Though the G2 PAMAM dendrimer showed less interaction with $\mathrm{Rh}_{6 \mathrm{G}^{[17]}}$, the G2 POSS-core dendrimer can efficiently capture Rh6G without changing the fluorescence spectra of Rh6G after the complexation. The fluorescence intensity was monitored after UV irradiation with the 120 low pressure mercury lamp at $25^{\circ} \mathrm{C}$. The fluorescence emission obtained from the aqueous solution containing $1 \mu \mathrm{M}$ Rh6G in 50 $\mathrm{mM}$ sodium phosphate buffer $(\mathrm{pH}=7.0)$ was greatly reduced to $10 \%$ after 5 min UV irradiation (Fig. 3b). In the presence of $10 \mu \mathrm{M}$ G2 PAMAM dendrimer, the fluorescence emission of Rh6G was 125 reduced to $60 \%$ after irradiation. Markedly, the fluorescence emission from the sample containing the G2 POSS-core dendrimer remained approximately $90 \%$ after $5 \mathrm{~min}$ irradiation. This significant advantage of the entrapment into POSS-core dendrimers to suppress the optical degradation should be valuable for the 130 experimental usages of common imaging probes as well as fluorescence dyes.

In conclusion, we described here that the POSS core can enhance the entrapping ability to the dendrimers. Compared to the G2 PAMAM dendrimer, a larger amount of guest molecules such 135 as hydrophobic aromatic rings or fluorescence dyes can be captured by the G2 POSS-core dendrimers. In addition, effective inhibition from the fluorescence photobleaching of the entrapped molecules was accomplished. Though there remains room to investigate the toxicity and the releasing ability of the POSS-core dendrimers for 140 practical usage as the carrier in drug delivery or in vivo imaging, this work suggests the potential widespread application of POSScore dendrimers not only for medicinal science but also for biotechnology.

\section{Notes and references}

1451 R. Esfand, D. A. Tomalia, Drug Discov. Today, 2001, 6, 427; D. A. Tomalia, L. A. Reyna, S. Svenson, Biochem. Soc. T., 2007, 35, 61; X. Shi, I. J. Majoros, J. R. Baker, Mol. Pharm., 2005, 2, 278; C. Kojima, K. Kono, K. Maruyama, T. Takagishi, Bioconjugate Chem., 2000, 11, 910.

1502 R. van Heerbeek, P. C. J. Kamer, P. W. N. M. van Leeuwen, J. N. H. Reek, Chem. Rev., 2002, 102, 3717; S. M. Grayson, J. M. J. Fréchet, Chem. Rev., 2001, 101, 3819; D. Astruc, F. Chardac, Chem. Rev., 2001, 101, 2991; T. Mizugaki, M. Murata, S. Fukubayashi, T. Mitsudome, K. Jitsukawa, K. Kaneda, Chem. Commun., 2008, 241;

155 M. A. Castriciano, A. Romeo, M. C. Baratto, R. Pogni, L. M. Scolaro, Chem. Commun., 2008, 688.

3 J. F. G. A. Jansen, E. M. M. de Brabander-van den Berg, E. W. Meijer, Science, 1994, 266, 1226; H. Martin, H. Kinns, N. Mitchell, Y. Astier, R. Madathil, S. Howorka, J. Am. Chem. Soc., 2007, 129, 9640; J. F. G. A. Jansen, E. W. Meijer, J. Am. Chem. Soc., 1995, 117 4417; S. Xu, Y. Luo, R. Haag, Macromol. Biosci., 2007, 7, 968.

4 N. Satoh, T. Nakashima, K. Kamikura, K. Yamamoto, Nat. Nanotechnol., 2008, 3, 106; O. Varnavski, R. G. Ispasoiu, L. Balogh, D. Tomalia, T. Goodson III, J. Chem. Phys., 2001, 114, 1962; R. W.

165 J. Scott, H. Ye, R. R. Henriquez, R. M. Crooks, Chem. Matter., 2003, 15, 3873; R. W. J. Scott, O. M. Wilson, R. M. Crooks, J. Phys. Chem. $B, 2005,109,692 ;$ H. Lang, R. A. May, B. L. Iversen, B. D. Chandler, J. Am. Chem. Soc., 2003, 125, 14832; D. A. Tomalia, A. M. Naylor, W. A. Goddard III, Angew. Chem. Int. Edn. Engl., 1990, 29, 138.

1705 K. Naka, M. Fujita, K. Tanaka, Y. Chujo, Langumuir, 2007, 23, 9057.

6 P.-A. Jaffrés, R. E. Morris, J. Chem. Soc., Dalton Trans., 1998, 2767; F. J. Feher, K. D. Wyndham, Chem. Commun., 1998, 323; F. J. Feher, K. D. Wyndham, D. Soulivong, F. Nguyen, J. Chem. Soc., Dalton Trans., 1999, 1491; X. Zhang, K. J. Haxton, L. Ropartz, D. J. Cole-
7 G. Caminati, N. J. Turro, D. A. Tomalia, J. Am. Chem. Soc., 1990, $112,8515$.

8 L. Fernandez, M. Gonzalez, H. Cerecetto, M. Santo, J. J. Silber, Suplamol. Chem., 2006, 18, 633.

1809 See Figure S1 in the Supporting Information.

10 See Figure S2 in the Supporting Information.

11 G. Weber, F. J. Farris, Biochemistry, 1979, 18, 3075; R. B. MacGregor, G. Weber, Ann. N.Y. Acad. Sci., 1981, 366, 140; F. G. Prendergast, M. Meyer, G. L. Carlson, S. Iida, J. D. Potter, J. Biol. 185 Chem., 1983, 258, 7541; R. B. MacGregor, G. Weber, Nature, 1986, 319, 70-73; K. Tainaka, K. Tanaka, S. Ikeda, K. Nishiza, T. Unzai, Y. Fujiwara, I. Saito, A. Okamoto, J. Am. Chem. Soc., 2007, 129, 4776.

12 C. Eggeling, J. Widengren, R. Rigler, C. A. M. Seidel, in Applied Fluorescence in Chemistry, Biology and Medicine (Eds.: W. Rettig, 190 B. Strehmel, S. Schrader, H. Seifert), Springer, Heidelberg, 1999, pp.193.

13 E. Arunkumar, C. C. Forbes, B. D. Smith, Eur. J. Org. Chem., 2005, 4051.

14 J. Mohanty, W. M. Nau, Angew. Chem. Int. Ed., 2005, 44, 3750.

19515 J. C. Mialocq, M. Meyer, P. Hébert, X. Armand, D. Lambert, Opt. Commun., 1990, 77, 185.

16 C. Eggeling, J. Widengren, R. Rigler, C. A. M. Seidel, Anal. Chem., 1998, 70, 2651.

17 Entrapping by the G2 PAMAM dendrimer was not confirmed because of less influence on UV spectra of Rh6G by the entrapping of the G2 PAMAM dendrimer. See Figure S4 in the Supporting Information. 